\title{
ENSINO, HISTÓRIA E EDUCAÇÃO COM/SEM CONVERGÊNCIAS
}

\author{
EDUCATION, HISTORY AND EDUCATION WITH/WITHOUT CONVERGENCE
}

\author{
Carlos Augusto Lima Ferreira ${ }^{1}$ \\ Marcella Albaine Farias da Costa ${ }^{2}$
}

\begin{abstract}
RESUMO: O presente texto tem por objetivo contribuir com reflexões acerca da história do Ensino de História ao problematizar questões relativas ao fazer docente nos processos de formação inicial. Visamos chamar a atenção dos profissionais, professores e alunos de História, para a importância do ensinar e pesquisar nos diferentes contextos de atuação desta área, de forma a avançarmos na superação de barreiras, dicotomias e hierarquias que nos impedem de caminhar. Dialogamos, portanto, com pesquisas que enxergam o ensino de História enquanto objeto e/ou com aquelas que o veem como campo de estudo, mostrando de que forma as expressões 'ensino', 'História' e 'Educação' tem ou não convergido ao longo do tempo.
\end{abstract}

Palavras-chave: Ensino de História. Formação Docente. Pesquisa Histórica.

ABSTRACT: This text aims at contributing with reflections on the history of the Teaching of History to problematize issues relating to making professor in processes of initial training. We aim to attract the attention of professionals, teachers and students of History, to the importance of teaching and researching in different contexts of performance of this area, so that we can make progress in overcoming barriers, dichotomies and hierarchies, which prevent us from walking. We talk therefore, with research that seeing that the teaching of history as the object and/or with those who see it as a field of study, showing how the expressions 'teaching', 'History' and 'Education' has or not converged over time.

Keywords: Teaching of History. Teacher Education. Historical Research.

\footnotetext{
1 Professor Titular da Universidade Estadual de Feira de Santana (UEFS), atuando no Programa de Pós Graduação em História (mestrado) e nos cursos de Graduação em História e Pedagogia. Doutor em Educação pela Universitat Autònoma de Barcelona.

2 Professora substituta de Prática de Ensino de História e Didática Especial de História na Faculdade de Educação da Universidade Federal do Rio de Janeiro (FE/UFRJ) e professora de História na Educação Básica (anos finais do Ensino Fundamental). Doutoranda em História pela Universidade Federal do Estado do Rio de Janeiro (UNIRIO).
} 
Sou estudante do Curso de Licenciatura em História da Universidade do Estado da Bahia - UNEB. Em conversa com minha orientadora a Professora Scarlet Hoffman ${ }^{3}$, falei do (...) meu interesse em fazer mestrado em História, a questão é que eu estou pesquisando na minha monografia Ensino de História, (...), como o saber histórico escolar vem sendo produzido no Colégio Polivalente de Conceição do Coité-BA. Isso me preocupa, por reconhecer que para se entrar em um Programa de Pós-graduação em História pesquisando Ensino de História é uma tarefa árdua, visto que, não se sabe o porquê, mas pesquisa dessa natureza, é melhor aceita em Programas de Pós-graduação em Educação.

Porém, eu quero fazer em História. (Depoimento do Estudante de História)

Este diálogo acontecido, via e-mail, foi um estímulo para que desenvolvêssemos as reflexões contidas neste texto e que objetivam contribuir com o debate, bem como chamar a atenção dos profissionais, professores e alunos de História, para a importância do ensinar e pesquisar nos diferentes contextos de atuação desta área, apesar dos desafios e dificuldades, notadamente na graduação. A Universidade é o lugar de contestação, debates, análises críticas, formação de opinião... lócus que define e imprime significados ao espaço físico das salas de aula em seus diversos cursos.

Ao observarmos alguns aspectos presentes no processo da formação docente, atentando para o curso de licenciatura em História, surge uma série de questões que avaliam a contribuição do conhecimento adquirido no espaço da graduação para o exercício da prática de ensino pelos alunos egressos da universidade. Dentre as questões identificadas, a percepção de que grande parte do que se aprende na universidade não foi elaborado com base nos desafios a serem vivenciados no cotidiano do oficio de professor. Evidencia-se um distanciamento das atividades realizadas no espaço acadêmico (debates, produção acadêmica, análise bibliográfica, transmissão e produção desse conhecimento, etc.) da produção de um conhecimento pedagógico - um saber a ser ensinado nas salas de aulas das escolas da educação básica.

Fenelon (1982) a esse respeito nos diz:

3 Nome fictício para preservar o anonimato da professora. 
Se aceitamos então essa dissociação referida acima entre a ciência e o social, sem a devida perspectiva crítica, estamos assumindo na prática um modo de pensar a nossa disciplina, a História, e o seu ensino e a pesquisa, dentro de um esquema tradicional, onde a Universidade é sempre pensada como centro de produção do saber, ou como diria Michel Certeau, ela se transforma no "lugar social" de onde falam os cientistas [...] E assim a ciência que se produz neste espaço social está circunscrita a ele, começa e acaba nele, produzida, consumida e criticada, revista e analisada dentro de um círculo cada vez mais fechado que lhe determina o permitido e o interdito. (FENELON, 1982, p.23-35).

A própria organização curricular do curso de História, transmite a dicotomia entre as chamadas "disciplinas específicas" do curso e as "disciplinas pedagógicas" necessárias, fomentando ao falso entendimento de que há disciplinas sem caráter pedagógico, quando a própria disciplinarização é uma ação pedagógica. Além disso, identifica-se uma compreensão de complementaridade atribuída às "disciplinas pedagógicas" em relação às demais disciplinas, dando-Ihes a falsa impressão de irrelevância para a formação do acadêmico de História, identificada, na prática, pela atitude de desinteresse e desprezo dos graduandos às chamadas "disciplinas pedagógicas"4. Nesse momento, rememoramos uma questão peculiar, que felizmente começa a ser revista, agenciada por determinadas inquietações das consequências de um anseio pessoal dos professores da área de Pedagogia. Espera-se que a universidade garanta aos formandos, ao concluírem seus cursos, um "manual de como ser professor!". Entretanto, não é isso que almejamos ou propomos.

Quando começamos a discutir sobre o ensino de História, no início dos anos 1980, tínhamos um argumento infalível para justificar a inserção no debate sobre a temática: é bem verdade que não havia uma profusão de estudos e pesquisas sobre o tema para contribuir e subsidiar teoricamente aqueles que tivessem interesse investigativo. Tínhamos um álibi poderoso que justificava as posturas, sempre que se discutia o ensino e a formação de professores. A não existência

\footnotetext{
${ }^{4}$ Sobre esse aspecto, precisamos pensar na herança do modelo de educação superior denominado de "3+1". Tal modelo, criado no Brasil nos anos 1930, é pautado na racionalidade técnica e científica aplicacionista. Neste sistema, as disciplinas pedagógicas, com duração de um ano, são justapostas às disciplinas de conteúdo específico, que duram três anos.
} 
da pesquisa, bem como a falta de uma sólida e consistente bibliografia nos absolvia!

Uma providencial justificativa, que de fato, encontrava respaldo para a ausência dos trabalhos de Ensino de História parecia distante e que pouco fazia parte do nosso universo formativo. Podemos lembrar, por exemplo, do curso da Pós-graduação em Metodologia e Didática do Ensino Superior em que, por mais que debatêssemos sobre o tema em questão, ainda era uma discussão incipiente, mesmo com o repertório de leitura que referendava Cabrini, Silva, Freire e Fenelon. Pode ser que alguns tenham sido esquecidos, mas, em geral, eram a esses autores que recorríamos para refletir sobre o Ensino de História e sobre a formação de professores.

O ensino de História, para o governo da ditadura civil-militar, era encarado como questão estratégica e fundamental para os planos de difusão do projeto político a ser implementado na sociedade brasileira. Para concretizarem tais objetivos, os generais foram taxativos, como nos informa Ricci: "A História representa valioso papel na conservação e no fortalecimento do Poder Nacional, mormente em épocas críticas como esta em que estamos vivendo" (RICCI, 1992, p. 19).

A lógica desta política, desenvolvida pelos militares, justificava-se em função de estarmos vivendo, naquele momento, um período de repressão política. Nesta perspectiva, é possível entender a razão e quais as consequências para a formação do professor. A História constituía-se, assim, como um espaço que deveria ser fiscalizado e controlado em nome da Política de Segurança Nacional. Sobre esta questão Circe Bittencourt nos aponta que "de um modo geral, rejeitavam-se os Estudos Sociais, que pretendiam - tirando da História e Geografia seus métodos próprios de produção de conhecimento - excluir do ensino as possibilidades de crítica à realidade brasileira" (BITTENCOURT, 1997, p. 40).

Ao longo desse processo, ocorria, ao mesmo tempo, uma desqualificação dos professores de História, bem como uma massificação e proliferação dos livros didáticos, reprodutivistas, factuais e compromissados com a história oficial. Esta política, segundo Freire (1993), além de tornar o comportamento destes 
profissionais passivos diante das circunstâncias, bloqueia-lhes a possibilidade de construir, de criar e de acreditar em transformações. Desta forma, ocorre a desvalorização do professor, levando-os a condição de parentes "postiços" dos alunos e a assumirem o papel de tias e tios. Ainda nesta direção, Freire, no livro intitulado Professora Sim, Tia Não, conclui:

O que me parece necessário na tentativa de compreensão do enunciado professora, sim; tia, não, se não é opor a professora à tia é também identificá-las ou reduzir a professora a condição de tia. (...) Isto não significa, porém, que a tarefa de ensinar transforme a professora em tia de seus alunos da mesma forma como uma tia qualquer não se converte em professora de seus sobrinhos só por ser tia deles. Ensinar é profissão que envolve certa tarefa, certa militância certa especificidade no seu cumprimento enquanto ser tia é viver uma relação de parentesco... (FREIRE, 1993, p. 10-11).

Percebe-se, assim, que o ensino de História no Brasil, notadamente na década de 1970, caracterizou-se:

[...] de um lado, pela existência de uma história única e já pronta para ser transmitida; de outro, de uma história cuja noção introjectada favorecia a legitimação da memória dos dominantes e dificultava a efetivação de experiências que rompiam com o modo tradicional de ensino de História (FONSECA, 1993, p. 11).

Algumas mudanças começam a acontecer no final da década de 1970 e em meados de 1980 (ocaso da ditadura militar), quando História e Geografia voltam a existir como disciplinas autônomas, nas últimas séries do $1^{0}$ grau ( $7^{a}$ e $8^{a}$ ) e no $2^{\circ}$ grau $\left(1^{\circ}, 2^{\circ}\right.$ e $3^{\circ}$ anos). Inicia-se, também, um processo de reforma dos currículos.

Com a redemocratização do país a partir de 1985, uma luta por mudanças, novas abordagens e novos currículos de História, começou a ser travada pela comunidade de professores, tendo a Associação Nacional de História - ANPUH - à frente, buscando soluções para a questão do ensino de História.

Os debates levaram ao enfrentamento das questões principalmente em duas vertentes: modernização dos currículos de $10,2^{\circ}$ e $3^{\circ}$ graus e a qualificação e atualização de professores de História. Muitos esforços, recursos humanos e financeiros foram e estão sendo dispendidos nesse sentido em vários estados do Brasil, por parte de Secretarias de Educação, 
Instituições de Ensino Superior e de $1^{\circ}$ e $2^{\circ}$ graus (SCHMIDT, 1997, p. 54, grifo nosso).

Na Bahia, como de resto no Brasil, depois de uma longa e árdua discussão, as diretrizes curriculares estaduais de 1986 trazem essa proposta de mudança, defendida pelos especialistas da área, buscando a revalorização das duas disciplinas e a extinção de Estudos Sociais.

No entanto, mesmo com as constatações anteriores, as décadas de 1980 (a partir da redemocratização) e 1990 são extremamente importantes para o ensino da História, pelo empenho e o esforço dos profissionais que tiveram por objetivo a (re)valorização da disciplina como conhecimento fundamental na formação do pensamento crítico do cidadão. Um desses caminhos ocorre com a divulgação das correntes historiográficas, que colocam em evidência novos temas e novos objetos para o conhecimento histórico.

Tornaram-se objetos e sujeitos do conhecimento histórico os "excluídos da história" como a mulher, a criança, o negro, o índio, o trabalhador e o idoso. Os temas foram extraídos do contexto das relações sociais existentes no cotidiano, presentes no imaginário social, na história das mentalidades e na vida privada.

Essa nova postura historiográfica torna-se relevante, via de regra, nos meios acadêmicos, embora haja muito por se fazer para que estas novas dimensões cheguem ao ensino fundamental e médio. Evitando-se, dessa forma, o fosso entre a universidade e a escola. Assim, os meios universitários estarão rompendo com a tradicional distância, uma vez que:

\footnotetext{
Procura-se dar voz aos excluídos, ora tentando introduzir novos materiais, novas fontes, novas questões sobre os esquemas preexistentes. [...] As propostas expressam a necessidade histórica de trazer para o centro da reflexão, ações e sujeitos até então excluídos da História ensinada na escola fundamental (FONSECA, 1993, p. 109).
}

Por conseguinte, como aponta com singular propriedade Silva (1995), é preciso não só criticar uma concepção de história conservadora e reprodutora do modelo dominante, mas alertar os intelectuais, professores e alunos universitários para o fato de que a academia deve ter uma prática diferente da que até então vem sendo desenvolvida: 
Enquanto graduados em história têm dificuldades para se assumirem como historiadores, muitos historiadores que lecionam em universidades não se vêem como professores. Reforçam o descompromisso do ensino superior com o prazer da história para todos, deixando de assumir responsabilidades na preparação de seus próprios alunos para ensino e pesquisa, desqualificando-os por não saberem línguas estrangeiras nem técnicas de pesquisa e estudo (em lugar de reconhecerem o aprendizado dessas e outras habilidades como tarefas da universidade). Contribuem, assim, para a reprodução ampliada daquela desqualificação. Na medida em que a escola não é encarada como patrimônio histórico, legitima-se mais a degradação do ensino, com prédios e equipamentos destruídos ou escondidos por outdoors, professores pessimamente remunerados, obrigados a fazer sofridas greves, alunos sem aprender e 'altos estudos' apropriados por minorias muito (o)cultas (SILVA, 1995, p. 83-84, grifo nosso).

Tais questões envolvem fatores que circunscrevem determinados espaços: a universidade enquanto lócus de produção de conhecimento científico, e enquanto espaço de formação de profissionais, no caso, professores ou profissionais da educação; e a escola, em suas dimensões de local de trabalho desses profissionais. Mas, devemos, todavia, superar o distanciamento entre a universidade, caracterizada como aquela na qual se produz o saber, e o ensino fundamental e médio, qualificado como aquele que tem como tarefa única e exclusiva transmitir este conhecimento "produzido" pela universidade.

Refletindo sobre o papel da universidade, Miceli (1988) amplia e dá uma maior visibilidade a essa discussão, quando atribui à hierarquização dos níveis a cristalização do distanciamento entre a universidade e o ensino médio. Segundo ele,

A expressão ensino superior também produz, em contrapartida (= equivalência), não a sua complementação, mas o seu contrário: existe um ensino inferior. Sendo o ensino do terceiro grau o superior, os níveis anteriores são, portanto, inferiores... Mas, inferior/superior em relação a quê? Essa hierarquização - perigosa e elitista, além de imobilizadora - atribui funções e papéis específicos e extremamente diferenciados a cada um dos níveis de escolaridade: ao ensino universitário (o superior...) compete produzir conhecimentos para consumo do ensino inferior (MICELI, 1988 , p. 104-105). 
O ensino superior ainda vê o ensino fundamental e médio como áreas de intervenção dissociadas de sua própria realidade, mas os problemas vivenciados nas escolas públicas estão em certa medida sendo vivenciados por alunos e professores no ensino superior. Por conseguinte, é necessário que se evite um gap entre a universidade e o ensino básico, fazendo com que as diversas produções oriundas da academia cheguem às salas de aula e que estas sejam um espaço para pensar, refletir e debater às questões enfrentadas pelos professores, a fim de contribuir com o processo de ensino aprendizagem. Mais do que isso: é primordial que se reconheça a escola como um local de produção - e não de mera reprodução - de conhecimento e de saberes em sua especificidade (MONTEIRO, 2007).

A História cristalizou-se ao longo dos anos como uma disciplina que nada ou quase nada acrescenta no processo de formação do educando, servindo, apenas, para a memorização dos fatos, dos grandes nomes da história e das datas oficiais, e ainda com o ônus de estudar algo distante da sua realidade, deslocado do seu universo.

O cenário da escola não problematizadora favorece que o ensino de História pouco desperte o aluno para a apreensão do conhecimento, já que, para eles, este ensino não tem utilidade, além de propiciar uma visão que assume o passado como a única possibilidade de análise histórica.

A este respeito, Hobsbawm (1998), em sua obra Sobre la Historia, descreve:

Cuando el cambio social acelera o transforma la sociedad más allá de cierto punto, el pasado debe dejar de ser el patrón sobre el que se traza el presente para pasar a ser como máximo un modelo de referencia. 'Tendríamos que recuperar las costumbres de nuestros antepasados' cuando ya no las seguimos ni se espera que lo hagamos. Esto significa que ha tenido lugar una transformación radical en el propio pasado, que se convierte - y debe convertirse en una máscara de la innovación, puesto que su misión ya no consiste en expresar la repetición de lo acaecido con anterioridad, sino determinadas acciones que, por definición, son diferentes de las que produjeran en otra época (HOBSBAWM, 1998, p. 26-27).

Para o autor, a análise do passado é importante como referência, jamais para vivermos nele. No entanto, os nossos professores do ensino fundamental e 
médio, via de regra, mantêm-se com construções e concepções do ensino de História ainda ligadas a um passado distante, periodizada de forma linear, divididas em momentos estanques.

Nessa perspectiva, compreendemos a História não como a ciência do passado, mas como ensina Bloch (2002), a "ciência do homem no tempo". Um tempo que não se deixa capturar pela cronologia, um tempo atento aos problemas, aos conflitos e às tensões. Em sendo assim, uma História cuja narrativa vá ao encontro da realidade, mesmo sabendo que ela sempre será uma busca. Uma narrativa que traga as fontes, todas elas, de forma que nada que tenha sido vestígio humano seja relegado ou negligenciado. Tecer uma história que atente para o trabalho do homem, para sua criação, para o seu fazer cotidiano.

Portanto, torna-se imprescindível, pois, desvelar e repensar o ensino de História. Como bem retrata Hobsbawm:

\footnotetext{
Es tarea de los historiadores tratar de arrancar dichas vendas, 0 , por lo menos, un poco alguna que otra vez; $y$, en la medida en que lo hagan, estarán en condiciones de decirle a la sociedad contemporánea algunas cosas de las que podrá beneficiarse, incluso en el caso de que se resista a aprenderlas. Por suerte, la universidad es la única institución del sistema educativo en la que a los historiadores se les ha permitido, e incluso se les ha animado, a hacer tal cosa (HOBSBAWM, 1998, p. 50-51).
}

E este repensar tem sido propagado nos últimos anos, notadamente, na produção didática que nos tem apresentado concepções de História que visam à superação da história factual, puramente narrativa e descontextualizada. Todavia, o que em realidade se apresenta nas escolas dos níveis básicos, é um ensino ainda refém dos livros textos em que os professores transmitem os "fatos" históricos como "verdades" definitivas, absolutas e cristalizadas. Este fazer pedagógico compromete o ensino de História e desestimula o processo de ensino aprendizagem.

A prática do ensino de História busca uma renovação e esta se insere em um novo panorama epistemológico que avança rapidamente no paradigma das ciências humanas: o de contrapor a herança positivista, em que o objeto de 
estudo era reduzido ao cientificismo a verdades absolutas e incontestáveis, levando a um cenário que considere a diversidade da História em sua dimensão social.

Por todas essas questões entendemos que não podemos estudar história, educação ou o próprio processo de ensino-aprendizagem da história como sendo algo descolado da realidade existente, distante e sem significado da nossa realidade de educadores. Necessitamos buscar o sentido de cada fato histórico dentro do movimento histórico do qual a educação e o ensino de História são produtos e que carregam consigo todas as contradições da sociedade do qual são frutos.

Nesta perspectiva, o historiador, hoje, tem a preocupação de compreender e analisar as vivências de diferentes sujeitos, isto é, de recuperar as experiências vividas das múltiplas categorias de trabalhadores do campo, da cidade, da indústria, dos pescadores, enfim do conjunto de sujeitos que compõem o tecido social. Assim, como nos diz Fonseca (2004):

\begin{abstract}
A história do ensino de história é um campo complexo, contém caminhos que se entrecortam, que se bifurcam, estando longe de circunscrever-se à formalidade dos programas curriculares e dos livros escolares. Suas múltiplas relações com as várias dimensões da sociedade, sua posição como instrumento científico, político, cultural, para diferentes grupos, indica a riqueza de possibilidades para o seu estudo e o quanto ainda há para investigar (FONSECA, 2004, p. 28).
\end{abstract}

Nos últimos anos a história da educação tem se dedicado a não somente aprofundar os estudos sobre instituições escolares, práticas escolares, vida de professores, entre outros. Mas igualmente a ampliar sua área de discussão acerca do currículo escolar. Contudo, são ainda poucos os estudos acerca do ensino de História. Fonseca (2004) realizou um levantamento acerca da produção historiográfica sobre o tema nos últimos dez anos e constatou que "raramente trabalhos desta natureza ultrapassam a marca de $18 \%$ do conjunto da produção sobre o ensino de História" (FONSECA, 2004, p. 29).

Quando são realizados estão mais diretamente ligados aos problemas do cotidiano escolar. A história da disciplina ensino de História no Brasil parece 
interessar muito pouco aos professores e aos historiadores da educação que a ela se dedicam. Todavia, existe uma produção, ainda que, recheada de lacunas.

O tema Ensino de História era ainda pouco pesquisado no meio acadêmico. No período de 1984 a 1989, foram produzidos, entre dissertações de mestrado e teses de doutorado e de livre docência na área de História, 1.729 trabalhos, dos quais apenas 13 abordam o ensino de História. O quadro agrava-se quando estes mesmos assuntos são apresentados em periódicos nacionais especializados em História, ou seja, de um total de 1.048 artigos produzidos entre 1961-1992, apenas $44(4,19 \%)$ discutem, especificamente, o ensino de História, enquanto que 1.004 artigos $(95,81 \%)$ discutem outros temas ligados à história e/ou à historiografia. Quando a produção é específica da área de educação, o quadro é o seguinte: dos 3.248 artigos produzidos entre 1944-1992, apenas 11 (0,33\%) são relativos ao ensino de História e 3.237 (99,67\%) abordam outros temas (NUNES, 1996, p.17-20).

Números mais atuais indicam que a temática é pouco discutida no seio acadêmico. Para o XXI Simpósio Nacional de História, realizado em julho de 2001, foram apresentadas apenas 30 comunicações $(5,6 \%)$ sobre o ensino de História num universo de 533 produções selecionadas para este evento. No XXII Simpósio Nacional de História realizado em julho de 2003, de um total de 284 trabalhos inscritos, 51 (18\%) artigos tratavam sobre o ensino de História, o que representou um avanço em relação ao encontro de 2001, mas que ainda é representativamente muito modesto.

Estes dados revelam que a falta de trabalhos sobre o ensino de História é um elemento relevante e que, mesmo na área específica de História, a produção acerca do tema ainda é restrita. Os estudos demonstram que a maior parte do volume da produção concentra-se na área de Educação, evidenciando, portanto, uma luta de campos.

Ao longo das últimas décadas, entre os anos 1985 e 2000, os estudos e pesquisas sobre o ensino de História começam a ganhar visibilidade. Aqui aponto um conjunto de autores da chamada historiografia do ensino de História no Brasil, com ênfase para as obras de Marcos Silva (História: o prazer em ensino e pesquisa), Conceição Cabrini (Ensino de História: uma revisão urgente), Elza 
Nadai (O Ensino de História e a pedagogia do cidadão), Jaime Pinsky (O Ensino de História e a criação do fato), Selva Fonseca (Caminhos da História ensinada), Silma do Carmo Nunes (Concepções de mundo no ensino de História), Circe Bittencourt ( $O$ saber histórico na sala de aula), entre outras e outros que contribuíram e influenciaram decisivamente novos pesquisadores.

As evidências sobre a produção acadêmica na área do ensino de História, com novos olhares, vão ganhando novos contornos, com o surgimento de encontros como o ocorrido no ano de 1993 na Universidade Federal de Uberlândia (UFU). Era o I Encontro de Pesquisadores na Área de Ensino de História - ENPEH, com apresentações e debates de trabalhos científicos tendo o ensino de História como objeto. A partir de então, o evento foi ampliado e passa a ser realizado, de dois em dois anos, nas seguintes instituições: Universidade Federal Fluminense (UFF), Universidade Estadual de Campinas (UNICAMP), Universidade Regional do Noroeste do Estado do Rio Grande do Sul (UNIJUÍ), Universidade Federal de Juiz de Fora (UFJF), Universidade Estadual de Londrina (UEL) e o último evento, o $X E N P E H$, congregando pesquisadores brasileiros e estrangeiros foi realizado em Aracaju, na Universidade Federal de Sergipe (UFS) no ano de 2013. Assim, vamos experimentando um aumento quantitativo e qualitativo das pesquisas na área do ensino de História. Ressalta-se, que nesse evento, foi criada a Sociedade Brasileira de Estudos e Pesquisas na área de Ensino de História.

Com a criação, nesse mesmo período, de um Grupo de Trabalho sobre Ensino de História e Educação na Associação Nacional de História (ANPUH), muito se contribuiu para um maior reconhecimento do campo de pesquisa sobre o Ensino de História. Com o intuito de observar a produção e o debate sobre o mesmo, nas últimas duas décadas, Fonseca (2004), a partir dos anais dos eventos específicos do campo, verifica os eixos temáticos que nortearam as discussões, em que ela atesta os avanços e os estreitamentos de relações entre a produção historiográfica e o Ensino de História, além de propostas para a utilização de novas linguagens e novas tecnologias.

A autora avalia também as produções mais recentes, como dissertações de mestrado e teses de doutorado, livros e capítulos de livros além de textos 
apresentados em eventos nas áreas de História e Educação. Apesar dos avanços em termos de aproximação entre o ensino e a produção historiográfica, há ainda, de acordo com a autora, muito que caminhar. Em várias linhas de pesquisa continuam os célebres "relatos de experiência", ligados ao cotidiano do ensino da disciplina e carecendo de fundamentação teórico-conceitual, uma ausência que parece teimar não ser superada. Portanto, ainda que com vagar, já não se podia e não se pode mais valer da justificativa da carência de estudos sobre o Ensino de História.

Por outro lado, queremos lembrar Cerri (2005), que juntamente com outros estudiosos, já indicavam, pelo menos desde o final da década de 1990, que a área de ensino de História e Educação são de olhares em convergência. Em texto que vale a pena revistar, apresentado por ele em 2005, nos Cadernos de História, da UFU, afirmava que:

O ensino de História vem se constituindo do trabalho de pesquisadores que estão institucionalmente ligados a História e à Educação, principalmente, valendo-se de conceitos, métodos e técnicas dessas e de outras ciências, e, portanto, institucionalmente o que existe não é ainda uma disciplina, mas uma área de interesse interdisciplinar que é compartilhada por profissionais diversos, dentro e fora da academia, e isso é de uma riqueza ímpar (CERRI, 2005, p. 8).

Apesar do que nos aponta Cerri (2005), diríamos que em realidade são olhares sem convergência, pois, via de regra, o que temos presenciado é a manutenção de barreiras, tal como corre objetivamente nos diversos concursos para Ensino de História. Entendemos que isso é empobrecer o campo de investigação, é forjar limites artificiais que impedem a circulação dos pesquisadores. A esse respeito, achamos primordial indicar a leitura do documento ${ }^{5}$ que o GT de Ensino de História e Educação produziu como resposta

\footnotetext{
${ }^{5}$ Cf. http://www.anpuh.org/gt/view?ID_GT=10. Nessa mesma perspectiva, não podemos deixar de lamentar o seguinte posicionamento: "Há rumores e vozes que a Anpuh agora é só ensino...". Que está registrado no vídeo da Jornada de História: Currículo da Educação Básica e Formação do Historiador: questões atuais e perspectivas. Encontro promovido pelo GT de Ensino de Ensino de História e Educação e a ANPUH em 29/05/2014 na Universidade de são Paulo - USP. Cf. http://www.youtube.com/watch?v=9_Pc0TYozh8\&feature=youtu.be http://www.youtube.com/watch?v=Pp92Txz3T6A\&feature=youtu.be
} 
as diversas solicitações encaminhadas por colegas que tinham e tem mestrado e/ou doutorado em educação, mas com graduação em História. Assim, temos consciência de que a dicotomia entre bacharelado e licenciatura, vistos por muitos como "mundos paralelos" e "mundos distantes", ainda é fortemente fixada nas narrativas de licenciandos com os quais dialogamos diariamente, mostrando claramente a desvalorização pela opção relativa ao ofício docente. Em recente pesquisa realizada por Costa (2015), percebemos isso de maneira explícita:

Lembro que falar que queria ser professora no início do curso era atestado de mediocridade. Alguns professores adoravam dizer isso. [...] Acho que o grande pecado do nosso curso é esse mundo paralelo entre bacharel e licenciatura. Querem que sejamos professores que dialoguem mais com seus alunos, mas isso não está presente no ambiente que estudamos (Licenciando 2, grifos nossos).

Superar estes limites, portanto, é condição sine qua non à formação do historiador, até porque, considerando o professor como tal, não procuramos estabelecer hierarquizações entre quem ensina e quem pesquisa. E aqui podemos trazer vários exemplos de que esta questão de hierarquização é muito pequena para não dizer uma questão irrelevante e sem sentido, ou seja, o lócus onde "[...] lutamos por mais espaço para as nossas ideias e posicionamentos, demarcamos territórios, ganhamos ou cedemos terreno, pensamos sobre o lugar de nossas propostas dentro do processo educativo, e assim por diante" (CERRI, 2001, p. 1).

\section{Concluindo... Ensino de História: um território a consolidar}

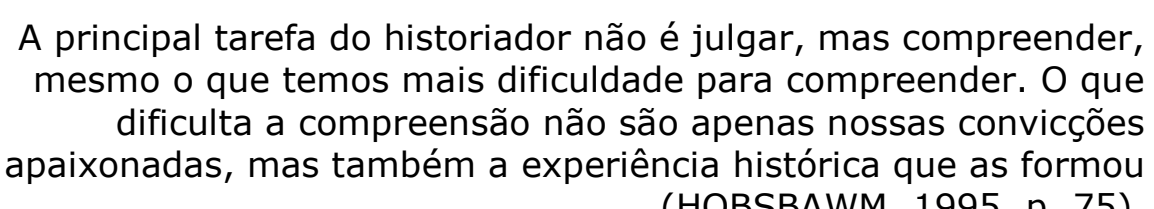

(HOBSBAWM, 1995, p. 75). 
Nos espaços dos encontros Perspectivas do Ensino de História e Pesquisadores do Ensino de História e em simpósios temáticos sobre Ensino de História realizados nos diversos eventos da Anpuh Nacional ou regional vem acontecendo cada vez mais a aproximação das pesquisas aos campos historiográficos, notadamente da Europa francesa e inglesa. Ou como nos diz Bitencourt (2004), estas pesquisas circulam entre historiadores brasileiros junto com novos objetos, métodos e problemas, novos desafios para se pensar a pesquisa e o ensino de história na universidade brasileira.

Desta maneira, a partir de trabalhos desenvolvidos por nós, queremos nos referir a uma experiência singular na disciplina de Estágio IV, ministrada na Universidade Estadual de Feira de Santana (UEFS), (no segundo semestre de 2013), onde foram realizadas oficinas de ensino tendo a história local como campo investigativo. Foram confeccionados pelos alunos 30 materiais didáticos (cartilhas), a partir de pesquisas, leituras de artigos e textos, discussões em grupos, discussões nas aulas, consultas bibliográficas, relatos orais e relatórios escritos das atividades. O conhecimento adquirido nas oficinas por estes alunos contribuiu para a reflexão e planejamento de atividades didáticas para o ensino na educação básica.

Compreendemos, portanto, que as linguagens estão presentes de forma intensa no nosso cotidiano, notadamente no universo das crianças e jovens, os estudantes desenvolveram atividades que discutiam o impacto da televisão, cinema, fotografia, histórias em quadrinhos, charges, músicas, entre outras, no cotidiano dos alunos da escola campo de estágio. As produções desenvolvidas a partir dessas oficinas de ensino favoreceram o processo de aprendizagem, constituindo-se em um espaço para os educandos da Educação Básica se perceberem como sujeitos do processo histórico.

Outro caso que desejamos mencionar refere-se à montagem e execução (em novembro de 2012) da oficina pedagógica "Comunicação tem História: muito além do bate-papo" no âmbito do PIBID/História-UFRJ. Entendendo que a escola, enquanto espaço de conhecimento, deve estar atenta às novas demandas da sociedade, o potencial desta atividade estava justamente em trazer para o espaço escolar assuntos rotineiros do cotidiano dos alunos, explorando os 
laboratórios de informática - espaços frequentemente negligenciados pelo corpo docente. A comunicação foi trabalhada, historicizando suas formas e usos de modo que os jovens refletissem criticamente sobre as apropriações que fazem das novas tecnologias (COSTA e DOMINGUES, 2013).

Deste modo, tal como exemplificado, pode-se estabelecer um diálogo estimulante com os participantes envolvidos com o ensino da História na Educação Básica e também com aqueles interessados pelos problemas de formação docente na área de História, a partir das articulações entre teoria e prática. Concordamos com Charlot (2006) de que precisamos sair dessa pseudoposição entre teoria e prática, até mesmo porque, como ele lembra, aquilo que se chama de prática, muitas vezes, está enraizado em teorias sem que necessariamente tenhamos consciência. Certamente essa é uma questão que não é nova e permanece como um desafio nos cursos de licenciatura na contemporaneidade. Estes aspectos oportunizam aos professores visualizar para além dos hábitos e conceitos adquiridos com a experiência e a formação inicial, por meio da sistematização do que ocorre em sala de aula. Assim sendo, os professores adquirem competências para analisar, refletir e debater as experiências contemporâneas de ensinar história diante das questões contemporâneas que precisam ser entendidas no universo dos que frequentam os lugares de formação de saberes.

Acreditamos que pensar a pesquisa sobre e no Ensino de História, pressupõe uma renovação e reposicionamento do papel do professor desta disciplina nas escolas de Educação Básica. Esse redirecionamento implica olhares diferenciados, tanto para as temáticas discutidas em sala, quanto para as fontes empregadas. Isto é, deve provocar a busca pela superação das relações hierarquizadas entre o ensino e a pesquisa em História. O momento convida para uma reflexão que leve em conta a noção de saber histórico e da sua produção oriundas de uma sólida formação acadêmica, para que o professor em formação se perceba também no papel de pesquisador. Enfim, uma articulação entre o ensino e a pesquisa sem hierarquias nem dicotomias, requisitos indispensáveis para a formação de docentes comprometidos com a constituição de outras 
práticas e saberes pedagógicos. E isso nos parece fundamental na prática e na formação dos nossos futuros docentes.

\section{Referências}

BLOCH, M. Introdução à História. Coleção Saber. São Paulo: Jorge Zahar, 2002.

BITTENCOURT, C. (Org.). O saber histórico na sala de aula. São Paulo: Contexto, 1997.

Os novos caminhos do ensino de história. Nossa História, Rio de Janeiro, p. 80-82, set. 2004.

CERRI, L. F. Ensino de História: Fronteiras interdisciplinares, avanços e problemas. Cadernos de História (UFU), Uberlândia, v. 12/12, n.1, p. 07-21, 2005.

CHARLOT, B. A pesquisa educacional entre conhecimentos, políticas e práticas: especificidades e desafios de uma área de saber. Revista Brasileira de Educação, v. 11, n. 31, p. 7-18, jan./abr. 2006.

COSTA, M. A. F. Currículo, História e Tecnologia: que articulação na formação inicial de professores? 2015. 145 f. Dissertação (Mestrado em Educação) Universidade Federal do Rio de Janeiro, Rio de Janeiro, 2015.

COSTA, M. A. F.; DOMINGUES, M. P. B. Escola, Ensino e Tecnologia: a oficina pedagógica "Comunicação tem História: muito além do bate-papo". In: Anais do XXVII Simpósio Nacional de História da ANPUH, Natal: Universidade Federal do Rio Grande do Norte, 2013, p. 1-14.

FENELON, D. R. A formação do profissional de História e a realidade do ensino. Projeto História, São Paulo, n. 2, p. 7-19, 1982.

FERREIRA, C. A. L. La Formación y la práctica de los profesores de Historia: enfoque innovador cambios de actitudes y incorporación de las nuevas tecnologías en las escuelas publicas y privadas de la provincia de Bahía, Brasil. 2004. 363f. Tese (Doutorado em Educación) - Universitat Autònoma de Barcelona, Barcelona 2004.

FONSECA, S. G. Caminhos da História ensinada. Campinas: Papirus, 1993.

FONSECA, T. N. de L. História e Ensino de História. Belo Horizonte: Autêntica, 2004. 
FREIRE, P. Professora Sim Tia Não: cartas a quem ousa ensinar. 2 ed. São Paulo: Editora Olho d'Água, 1993.

LE GOFF, J.; CHARTIER, R.; REVEL, J. et al. A Nova História. Coimbra: Almedina, 1990.

HOBSBAWM, E. Sobre la Historia. Barcelona: Crítica, 1998.

MICELI, P. O quadro (muito) negro do ensino no Brasil. In: SANFELICE, José Luís. (Org.). A universidade e $o$ ensino de $1^{\circ}$ e $2^{\circ}$ graus. Campinas: Papirus, 1988.

MONTEIRO, A. M. Professores de História: entre saberes e práticas. Rio de Janeiro: Mauad X, 2007.

RICCI, C. S. Da Intenção ao gesto - Quem é Quem no ensino de História em São Paulo. 1992. 130f. Dissertação (Mestrado em História) - Pontifícia Universidade Católica de São Paulo, São Paulo, 1992.

SCHMIDT, M. A. A formação do professor de História e o cotidiano da sala de aula. In: BITTENCOURT, C. M. F. (Org.). O saber histórico na sala de aula. São Paulo: Contexto, 1997, p. 54-66. 